\title{
The Voice of the Consumer on sVoD Systems During Covid-19: A Service Opportunity Mining Approach
}

\begin{abstract}
Electronic word of mouth (e-WOM) is a vital channel for the exchange of customer-generated content. As the e-WOM messages created by consumers pile all around the Web, they generate an unbiased voice about products and services. With their high-level production in online environments, e-WOM message contributions go far beyond consumer decision-making. They become a vital source for gaining insights on designing and improving marketing offerings. The purpose of the study is to analyze service improvement opportunities for subscription-based video-on-demand (sVoD) services by exploring customer-generated eWOM messages. In addition to this, the study aims to comprehend the effects of the COVID-19 pandemic on expectations, real feelings, and attitudes of customers towards its subscription-based video-on-demand services and to compare these emotions with those in the pre-pandemic period. Acting on customer-generated e-WOM messages for $\mathrm{sVoD}$ services, the paper provides a real-time analysis of monitoring customer needs and wants in a fast-moving service environment with topic-based sentiment analysis. The main procedures include data extraction and pre-processing, topic modeling, sentiment analysis, and opportunity analysis. When pre-covid and post-covid sentiments are compared, it is found that all sentiment scores have decreased, except for content diversity. The rich content offered by Amazon has led subscribers to take step to post positive comments about the platform. Addtionally, the results show possible service improvement opportunities in streaming quality, TV series content selection, use of commercials, and customer value generation in $\mathrm{sVoD}$ service encounters. The study identifies service improvement opportunities using data mining technology, which can provide a more in-depth understanding of consumer perceptions of marketing offerings and service quality. In addition, it analyzes the perceptions of consumers toward sVoD services in times of the Covid-19 pandemic.
\end{abstract}

Keywords: Video-on-demand services; topic modeling; sentiment analysis; Covid-19; customer reviews

\footnotetext{
*Y1ldız Technical University, Turkey. E-mail: ozansoy@gmail.com

** Istanbul Medeniyet University, Turkey. E-mail: agngor@yahoo.com

*** Ozyegin University, Turkey. E-mail: sena.kilic@ozyegin.edu.tr
} 
Received on: $2021 / 01 / 25$

Approved on: 2021/11/11

Evaluated by a double blind review system

\section{INTRODUCTION}

The ongoing COVID-19 pandemic has drastically affected what customers expect from the brands. It had a significant impact on the traditional film and TV industry (Luo, 2020). The industry has been disrupted by the suspension of the production of movies and TV shows due to the precautions taken to prevent COVID-19 (Mikos, 2020). Meanwhile, video streaming platforms, which are already on the rise, have become more attractive for consumers (Tashanova et al., 2020). People stay isolated in their homes for a long time, so they engage more with these online services (Dixit et al., 2020).

Subscription-based video-on-demand (sVoD) portals such as Netflix, Hulu, and Amazon Prime that provide online content for viewers (Wayne, 2018) have become a phenomenon as they reshape media services (Riekkinen, 2018). As the luring features of these portals, unlike television's linear scheduling of programs, they offer "bingeable" content (Susanno et al., 2019). Since sVoD portals eliminate the third party between the product and the viewer $(\mathrm{Wu}, 2013)$, viewers can control their watching schedules (Littleton, 2014). Besides allowing viewers to watch content whenever they want, they also provide flexibility about the devices (Noah, 2020).

With advanced technology and increasing popularity among customers, both the number of users and platforms have been growing for years (Gimpel, 2015). However, the pandemic has been the other driving force to consume different contents and switch between platforms. According to Leichtman Research Group (2020), sVoD portals such as Netflix, Amazon Prime, and Hulu are used by $78 \%$ of households in the U.S. in 2020, which was $64 \%, 69 \%, \% 74$ respectively in 2017, 2018, 2019 and a considerable number of them have subscribed more than one portal. Consequently, gaining new customers and retaining existing ones have become crucial for streaming service providers in this competitive environment (Kübler et al., 2020). 
In order to keep the current customers and gain new ones, it becomes essential for the firms to treat the customers in the way that their feelings and wishes are understood. Sentiment analysis and opinion mining have become potent tools for understanding customer opinions. Online user reviews can be used to predict customers' expectations, in addition to their interests, in any given context. Analyzing the sentiments in these reviews can provide factual information for service improvements. By applying machine learning algorithms, this study aims to understand the effects of the COVID-19 pandemic on Amazon customers' expectations from its streaming services by analyzing customer reviews. To the best of our knowledge, this study is the first that uses Amazon customer review data to reveal the emotions of the $\mathrm{sVoD}$ subscribers through sentiment analysis and find out the opportunities for service improvement by analyzing the topics that the consumers value the most. While doing so, the study also aims to compare pre and post-covid customer emotions. The results would guide all the platform owners in determining their services' negatives and positives since the study lets them benchmark with Amazon Prime consumer data. Also, as the first theoretical contribution, the study synthesized the topic modeling, sentiment analysis, and the opportunity map in one paper. Second, while defining the opportunities for improvement for the practitioners, the study bridges the gap in the literature by figuring out the effect of COVID-19 on the sentiments of the sVoD consumers. Third, this study contributes to the other studies that employ the data mining methodology by applying it to a different context.

\section{LITERATURE REVIEW}

Internet technology provides a good platform for consumers to share and forward their opinions and product evaluations online. An online review can provide information on many dimensions of e-commerce, including both information on the product and also add-on services. Over the years, academia was able to identify the strong relationship between product reviews and consumer decision-making (Thakur, 2018; Elwalda et al., 2016; Wang and Wang, 2010; Cruz et al., 2017). Online customer reviews as a form of e-WOM (Godes and Mayzlin, 2004) are a powerful marketing tool than other communication efforts initiated by the company as they are viewed as more credible (Constantinides and Fountain, 2008; Thakur, 2018; Bickart and Schindler, 2001). There are many studies in the literature regarding e-WOM, investigating the relationships between e-WOM and personal characteristics on social networks (Güngör and Çadırc1, 
2013), the effect of the quality of e-WOM on consumers' purchase intentions (Erkan and Elwalda, 2018; Lin et al., 2012), the impact of involvement and prior knowledge (Doh and Huwang, 2009), the motivational antecedents of e-WOM (Sijoria et al., 2018; Alhidari et al., 2015; Çadırcı Ozansoy and Sağkaya Güngör, 2015) to count some.

Customer reviews also have a critical role in online platforms due to the increasing significance of electronic word-of-mouth (eWOM) (Trenz and Berger, 2013). While WOM is an informal way of exchanging ideas on a particular product/service or seller, eWOM is the same concept in the online environment (Westbrook, 1987). eWOM is accounted as a credible source of information (Kim et al., 2019). It is so crucial that it can even be the deciding factor whether a customer would continue his/her relationship with a brand (Wang and Wang, 2010).

The effect of e-WOM on the promotion of services, including sVOD, has been receiving significant attention, significantly intensified after the COVID-19 pandemic. Researchers are working on the subject while considering the different aspects of eWOM. For example, Köster et al. (2021) compared social referrals (e-WOM) and organic search in consumers' engagement with sVOD services. Dogruel (2018) investigated the effect of cultural differences in individual decision-making for sVOD services by comparing German, the U.S., and Singaporean students. With a different approach, Abdullah and Artanti (2021) discussed the effect of situational factors, visual merchandising, and eWOM on consumers' impulsive buying of sVOD services. Nevertheless, no study in the literature compared the pre and post-pandemic customers' actual feelings regarding sVOD services, a subject this study aims to accomplish with Amazon Prime data.

Amazon, the world's largest e-tailer, is also the major player in the sVoD market, with 150 million paying Prime members worldwide by the end of 2019 (Amazon, 2019). In addition to this, it is the leader in the U.S. in terms of providing a wide range of genres in 2019 (Statista, 2020). Amazon has services that can both compete with conventional television channels and other video streaming platforms. In the literature, there are some studies that use Amazon data and apply text-mining techniques for different purposes like determining preferences of customers on online buying (Huang et., 2020), identifying effective online grocery shopping (Heng et al., 2018), and examining how cultural differences affect opinion about the features of the product (Wang et al., 2019). As customers share their experiences, attitudes, and consumption-related ideas online 
(Yaylı and Bayram, 2012) without any pressure, online customer reviews became a data source for many scholars ( $\mathrm{Li}$ and Hitt, 2010). Therefore, in this study, to understand the customers' real feelings and attitudes, online customer reviews are used to examine positive and negative expressions on streaming services, particularly for Amazon services of Prime Video and TV Networks (in short, Amazon Prime).

It is challenging to understand customers' expectations and attitudes in such competition, especially their experiences towards e-services (Vega et al., 2018). Various studies have been carried out for this purpose. For instance, Naratthawan (2021) surveyed to investigate the factors influencing customers' online media streaming services preferences. Brindha et al. (2020) preferred semi-structured interviews to analyze preferences for these services. E-WOM, especially in the form of customer reviews, can provide new ideas on service and product improvements (Anaya-Sánchez et al., 2016). In this sense, the current study moving beyond previous studies tries to establish an understanding of how online reviews can be used as an input in service development tools in sVOD systems.

\section{DATA AND METHODS}

To define possible service improvements in sVoD systems, we used Amazon customer review data on their prime video service from January 2019 to November 2020. The data consisted of 3,807 reviews, including the reviewers' identification, star ratings, review date, purchase verification, and the review text. R's tm package (v.0.7-7; Feinerer and Hornik, 2019) was used to clean and process customer reviews. In the first step, a corpus was constructed utilizing the review text. Second, the text was transformed to lowercase, and numbers, whitespaces, and special characters were cleaned from the corpus. In the third step stemming procedures were applied. In the last stage of data cleaning, irrelevant words were removed with stop word removal processes. The final corpus included a total of 142,424 terms and 3,567 documents. The corpus included 3,552 negative and 7,063 positive terms. Out of 3,567 documents, 392 were negative reviews, 2,113 were positive reviews, and the remaining 1,061 were neutral in terms of sentiments.

\subsection{Topic modeling}

Topic modeling is a probabilistic approach that has proceeded theory in detecting novelty and emergence as it helps us reveal the current and hidden structures in texts 
(Hannigan et al., 2019; Blei and Lafferty, 2009). Topic modeling promises multiple latent topics in the documents, and they can be unveiled by calculating distributions over terms (Blei, $\mathrm{Ng}$, and Lafferty, 2003). In this paper, the themes that run through the words of the texts were discovered based on their connections and evolution over time, and the hidden structures in the customer reviews of the $\mathrm{sVoD}$ services were revealed (Blei, 2012) with topic modeling algorithms. Based on the results, a set of topics were defined first, then the prevalence for each topic was calculated. Then, we assign titles to each topic. The model uses Dirichlet distribution, called Latent Dirichlet Allocation (LDA).

R's LDA package (v.1.4.2., Chang, 2015) was used for topic modeling. To determine the best number of topics, instead of applying the perplexity measure, a method trying to optimize the likelihood-based measures, however, ignores the human judgment, the Pointwise Mutual Information (PMI) method was used (Newman et al., 2010). PMI assesses the coherence of the model by observing word pairs in close proximity with Equation 1:

(1) $\operatorname{PMI}\left(w_{-} i, w_{-} j\right)=\log \left(p\left(w_{-} i, w_{-} j\right)+\varepsilon\right) /\left(p \llbracket\left(w \rrbracket \_i\right) p\left(w_{-} j\right)\right)$

$p(w):$ the probability of a word's presence in a given document $p(\omega i, \omega j):$ the probability of co-occurrence of the words

In this study, Normalized PMI (NPMI) was calculated with Equation 2 since it is correlated best with human judgment (Röder, Both, and Hinneburg 2015; Bouma 2009):

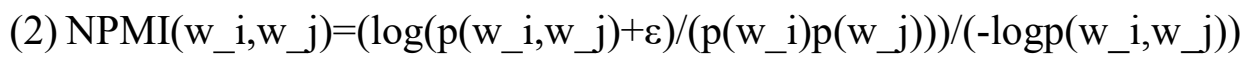

The model coherence calculation resulted in 10 topics for the model (Figure 1). 
Figure 1. Model Coherence

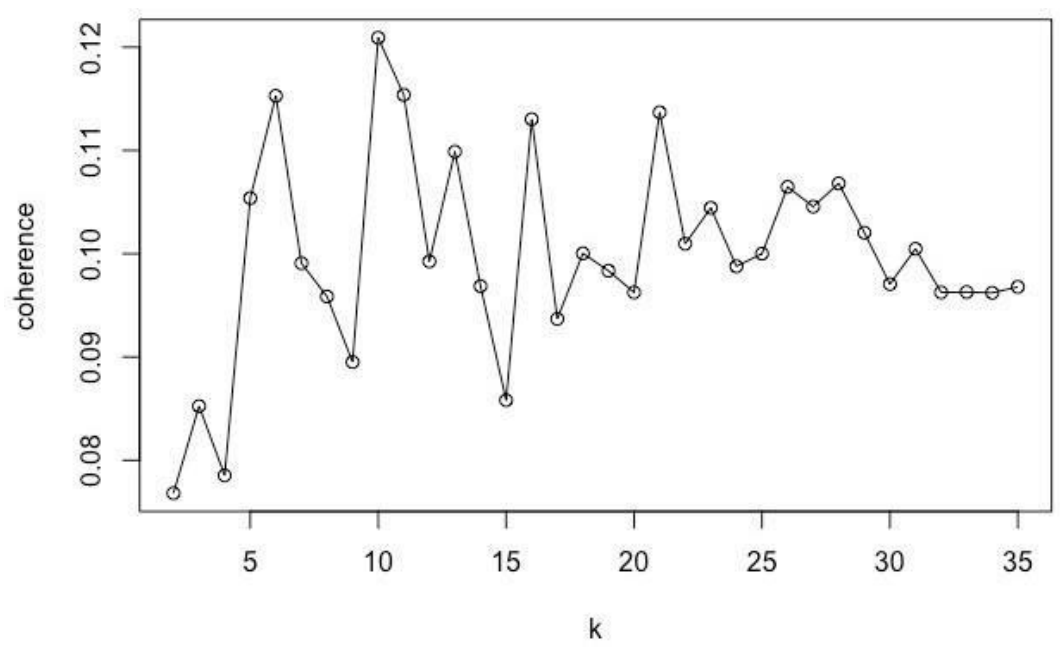

\subsection{Topic Naming and Topical Structure}

To interpret and understand the topics, we assigned names to each topic. In naming, the probability of a term assigned to a topic $\left(\varnothing_{-} \mathrm{kw}\right)$ is used as a typical application. But most of the time, the same words are observed under different topics. To overcome that problem, the term's relevance was used to rank the terms in our model (Sievert and Shirley, 2014) based on Equation 3.

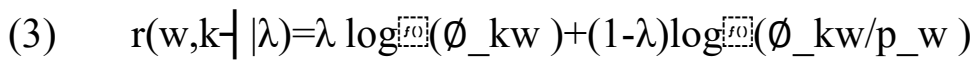

$\lambda$ : the weight that is given to a term $\omega$ under a topic $k$, relative to its lift

Following the literature, $\lambda$ was set to 0.6 (Sievert and Shirley 2014). The resulting topics and their defining terms are summarized in Table 1.

Analysis of the customer reviews gives us a tangible criterion to categorize the needs and measure the sVoD service's performance. This study uses Amazon Prime customer review data to apply topic modeling to categorize the customers' expectations, feelings, and needs within the Amazon Prime system. Service performance can be further evaluated on each topic to improve user satisfaction and experience regarding sVoD services. What is more, the resulting topics may be treated as the ones that should be considered by all sVoD service providers since, according to Statista, Amazon Prime is 
the market leader in the USA market (Statista, 2020). Therefore, there is a lot that others can learn from Amazon Prime.

Table 1. Topics and Terms of sVoD Services

\begin{tabular}{ll}
\hline Topics & Terms \\
\hline Content Variety & shows, love, good, wish, easy \\
Commercials & commercial, watch, show, fast, stop \\
Streaming Quality & service, streaming, quality, internet, stream \\
App Functionality & app, video, problem, device, account \\
User Interface & option, interface, new, search, user \\
TV Series & watch, episode, series, season, show \\
Customer Value Creation & time, money, customer, get, people \\
Movie & movie, selection, good, buy, old \\
Subscription and Membership & pay, free, membership, subscription, included \\
Competition & video, netflix, content, hulu, channel \\
\hline
\end{tabular}

Two topics in Table 1 may need further explanation before moving to the detailed analysis. They are "customer value creation" and "competition". The most intense two words in texts, defining customer value, are time and money. This topic addresses the subjects of customer perception of time value and monetary value. It is the satisfaction point of users getting value in return for their time and money. The other topic, "competition" includes and investigates the competing brands of Amazon Prime. The competition topic's sentiment's average being positive means that customers favor competing brands in their reviews over Amazon Prime.

\subsection{Sentiment Analysis}

Online customer reviews hold a lot of information, which help business owners predict users' interests. Along with opinion mining, sentiment analysis becomes a powerful tool to collect user reviews, analyze them, and develop emotions, attitudes, actual intents, and sentiments as the results (Sankar et al., 2020). It enables organizations to extract real insights from online mentions. In this study, the reviews' sentiment analysis helps us understand how the users are satisfied with the $\mathrm{s} V \mathrm{OD}$ services. 
Among the many different approaches available, two lexicon-based techniques were applied to reveal customers' sentiments and emotions in the current study. Pursuing the previous studies (Mohammad and Turney, 2010), to extract sentiments from customer reviews, R's "sentimentr" package (v.2.7.1; Rinker, 2019) and to extract emotions from the texts R's "syuzhet" package (v.1.0.6; Jockers, 2020) were used. Instead of other lexicons that use unigrams, because of the valence shifters-relied working principle, sentimentr was preferred.

\section{RESULTS AND DISCUSSION}

\subsection{Customer review sentiments}

Relying on the emotion lexicon dictionary of National Research Council (NRC), Canada, we described expressions based on eight primary emotions - anticipation, sadness, trust, anger, joy, disgust, surprise, and fear (Mohammad and Turney, 2010) and two sentiments -negative and positive-.

When we analyzed the corpus, trust became the most evoked emotion regarding $\mathrm{sVoD}$, closely followed by anticipation (Figure 2). The least evoked emotion is disgust. Therefore, the overall data sentiment analysis implies that the users are mostly satisfied with the sVoD service.

Figure 2. Emotions in Data

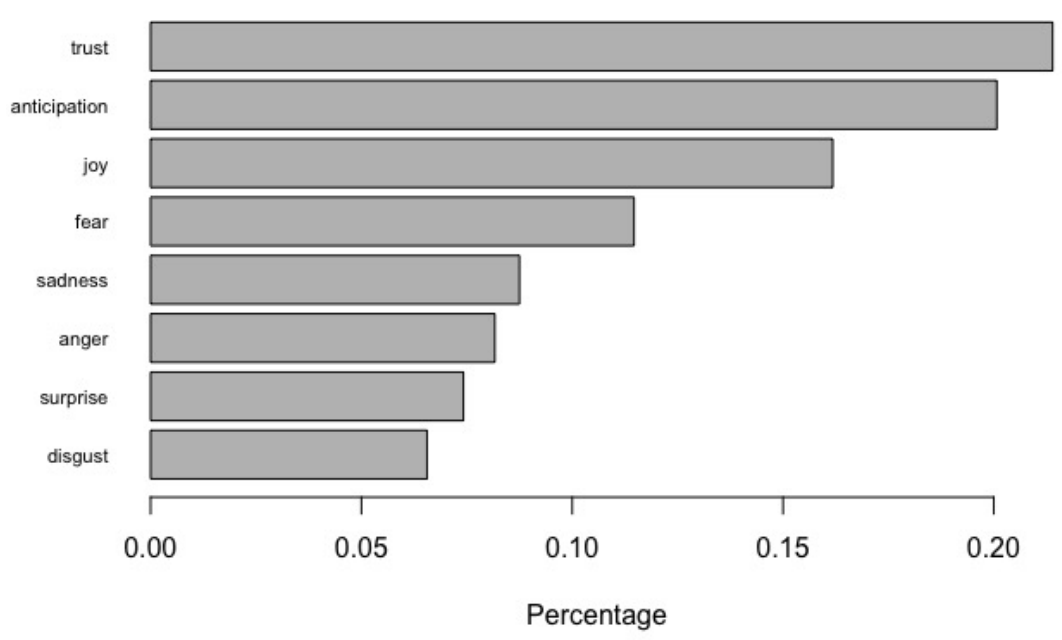

To go into detail, first, each topic is analyzed with its evoked sentiments on users. Figure 3 shows the positive and negative review valence of each topic. According to Figure 3, the positive peak is observed at subscription and membership, meaning that 
reviewers favor the easiness of the subscription process and subscription alternatives available to them. It is also visible on the opportunity map (Figure 8). The reviewers are also quite positive about the value created by the $\mathrm{s} V \mathrm{DD}$ service and the user-friendliness of the interface. And the most negative sentiment is observed in commercials. User reviews tell the service provider that this is a point that needs careful consideration, and it is entirely under the control of the platform owner.

The most apparent problem of the service provider, as observed in Figure 3, is the reviewers' positive sentiments regarding competitors. Although they have more positive feelings (compared to negatives) at almost all the aspects of the $\mathrm{sVoD}$ service provided by Amazon, there are still reviewers favoring the competitors, and what is worse, they are the subscribers (see Figure 5). The value of sentiment analysis lies in the fact that it reveals what the customers are positive about and gives information about the topics that the customers feel uncomfortable with. Moreover, business owners can have an idea about what their customers think about competitors. Thus, it is highly recommended to go into the details of the positive reviews about the competitors and find out what customers favor about their services.

Figure 3. Topic-Based Review Valence

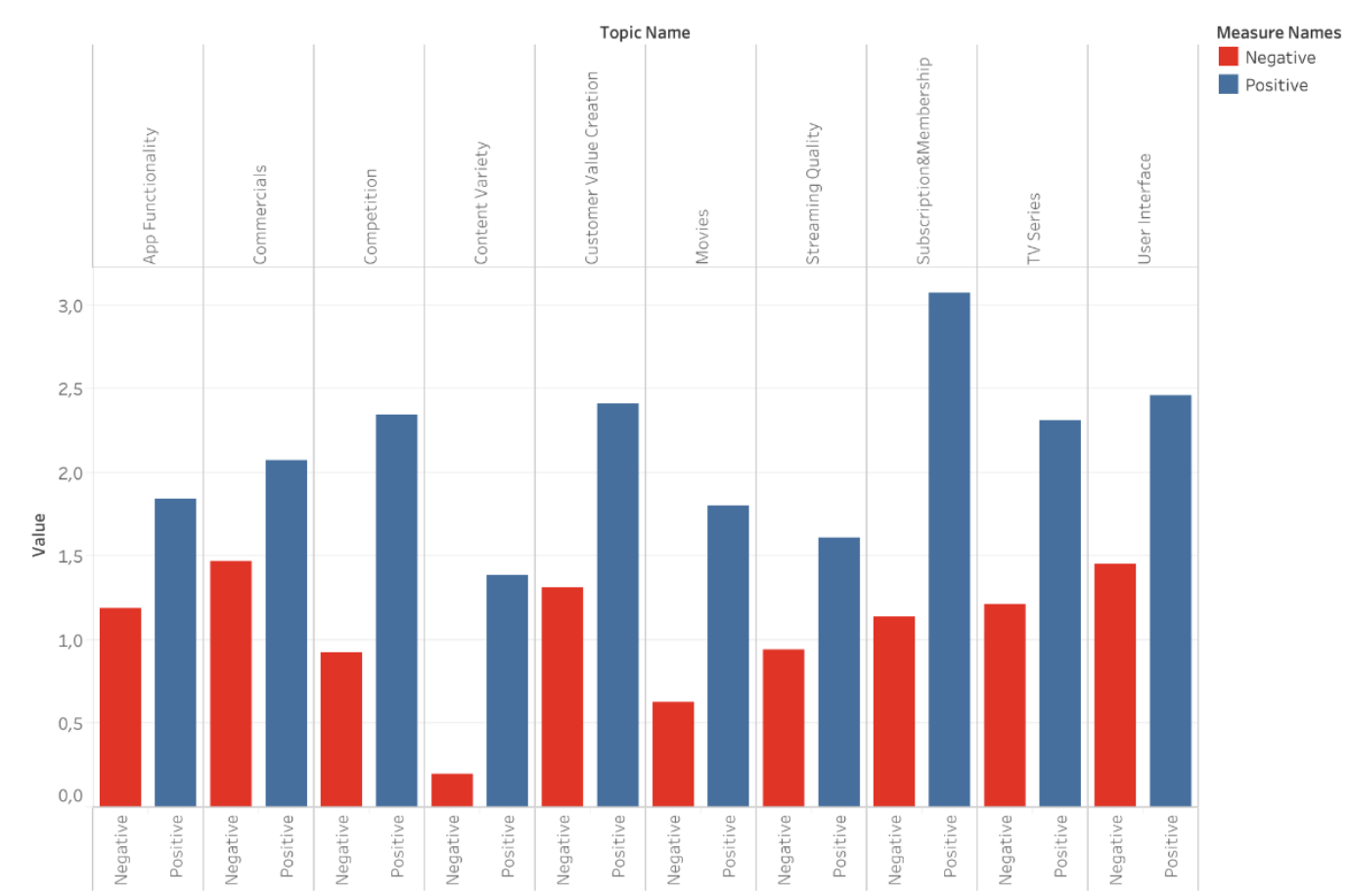


The sentiments and the emotions indicated by the overall data give us a general view of the actual feelings expressed within online mentions. To understand the exact sentiments associated with each topic, Figure 4 was developed. The most noticeable emotion in Figure 4 is associated with content variety, and it is joy. It indicates that users are enjoying themselves while they are watching, and they feel affirmative about the variety of content. Trust is the most realized sentiment all over the topics, as also observed in Figure 2. Another recognized emotion is the anticipation in subscription and membership. Anticipation, by definition, is an emotion that involves excitement and pleasure. As mentioned above (Figure 2), online mentions pointed out a satisfied subscription and membership process. Indeed, reviews are mostly positive (trust, joy, and anticipation are the most evoked emotions) about the TV series and movies, as also realized in content variety. And the highest observed anger is related to the commercials, again the topic that needs reconsideration. The topic of competition should also be mentioned as a vital part of the analysis. There is a small number of reviews about competition when compared to others. Although there is a little indication of anger, mostly trust, joy, and anticipation are evoked emotions in the reviews about competitors. The analysis reveals that it is a requirement to watch competitors closely. Furthermore, it could be a strategy to determine the most positive aspects that the consumers favor in the comments about competitors and consider putting them into practice on the platform.

Figure 4. Topic-Based Review Emotions

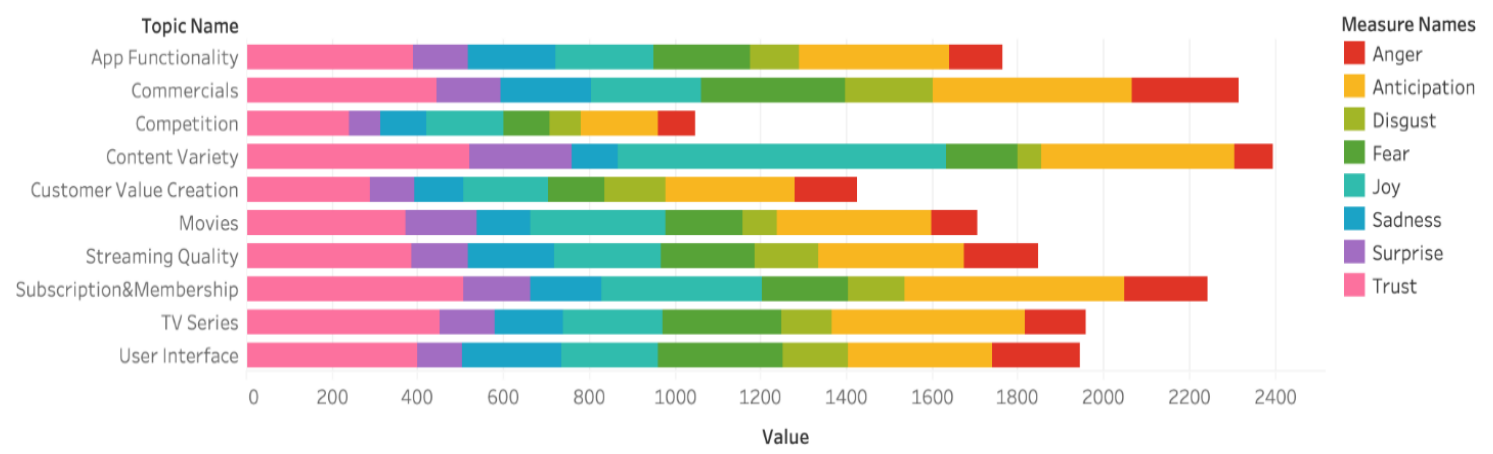

Customers can watch Amazon content in two different ways; they can subscribe to the Prime TV system or rent and buy content separately. At the next step, we still combine topic modeling outputs with sentiment analysis with breakdowns of subscribed and not subscribed users (Figure 5) and pre and post-covid situations (Figure 6). 
At the first step, the evoked emotions of the users who were already subscribed to the sVoD services were compared with the not subscribed users' emotions. Overall, subscribed users have quite positive reviews on all the topics, and the highest one was about the content variety, which is followed by the movies and streaming quality. Inconsistently, purchased users also favored the competitors in their reviews. On the other hand, the not subscribed users have either no emotions or negative emotions in almost all the topics. The only positive reviews are observed in content variety. The negativity (or somehow neutrality) of the not subscribed users is probably due to not knowing what the service can provide them. And the problem lies in the platform owner because they cannot promote the value created by $\mathrm{s} V \mathrm{oD}$ services enough.

Figure 5. Topic-Based Average Sentiments According to Subscription Status

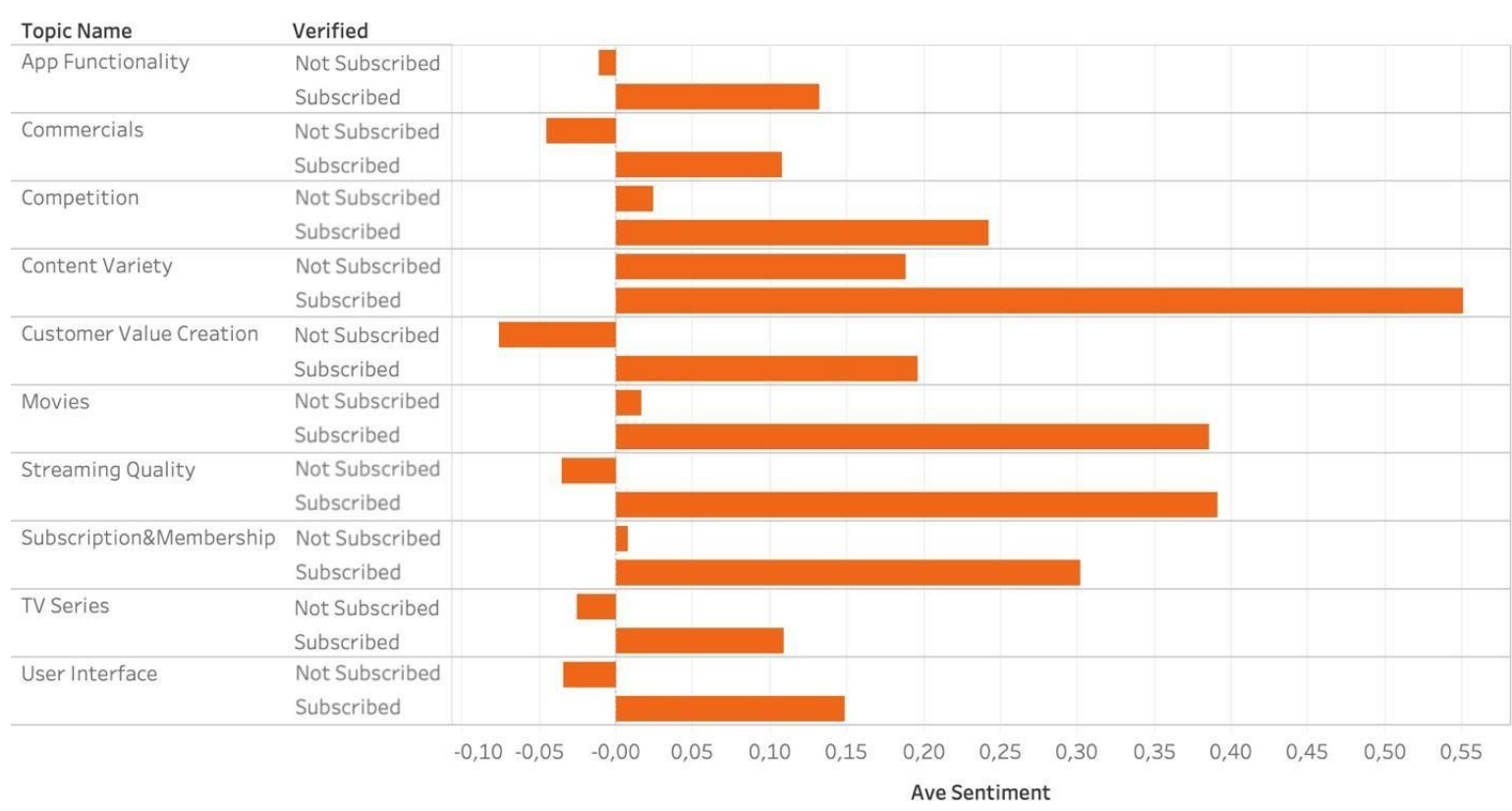

In the following step, we present a comparative study based on pre and post-covid emotions extracted from online reviews. Figure 6 illustrates the average sentiment score of each emotion evoked amongst sVoD service reviewers before and during Covid-19. From a general view, sentiment scores are decreasing during post-covid, except for content variety. There is even a slight increase in this topic's sentiments during postcovid. The rich content of the $\mathrm{sVoD}$ platforms adds value to the subscribers during lockdowns, and they rewarded Amazon with positive reviews.

There may be two explanations for decreasing positive sentiment scores during pandemics. 
According to Nielsen, there has been a $60 \%$ increase in the amount of video content consumed globally (Nielsen, 2020). Pursuing this fact, one of these explanations could be people are spending more time watching sVOD services, which is a good socially distanced entertainment, during lockdowns than ever before. So, their expectations become unfairly high compared to previous terms, and $\mathrm{sVoD}$ services fall short in meeting these expectations. As another explanation, the problem lies not only in the services supplied by the provider but also in the platform's users' adverse mental health because of the pandemic, causing them to express their feelings negatively in their reviews.

Figure 6. Topic-Based Average Sentiments Before and During Covid-19

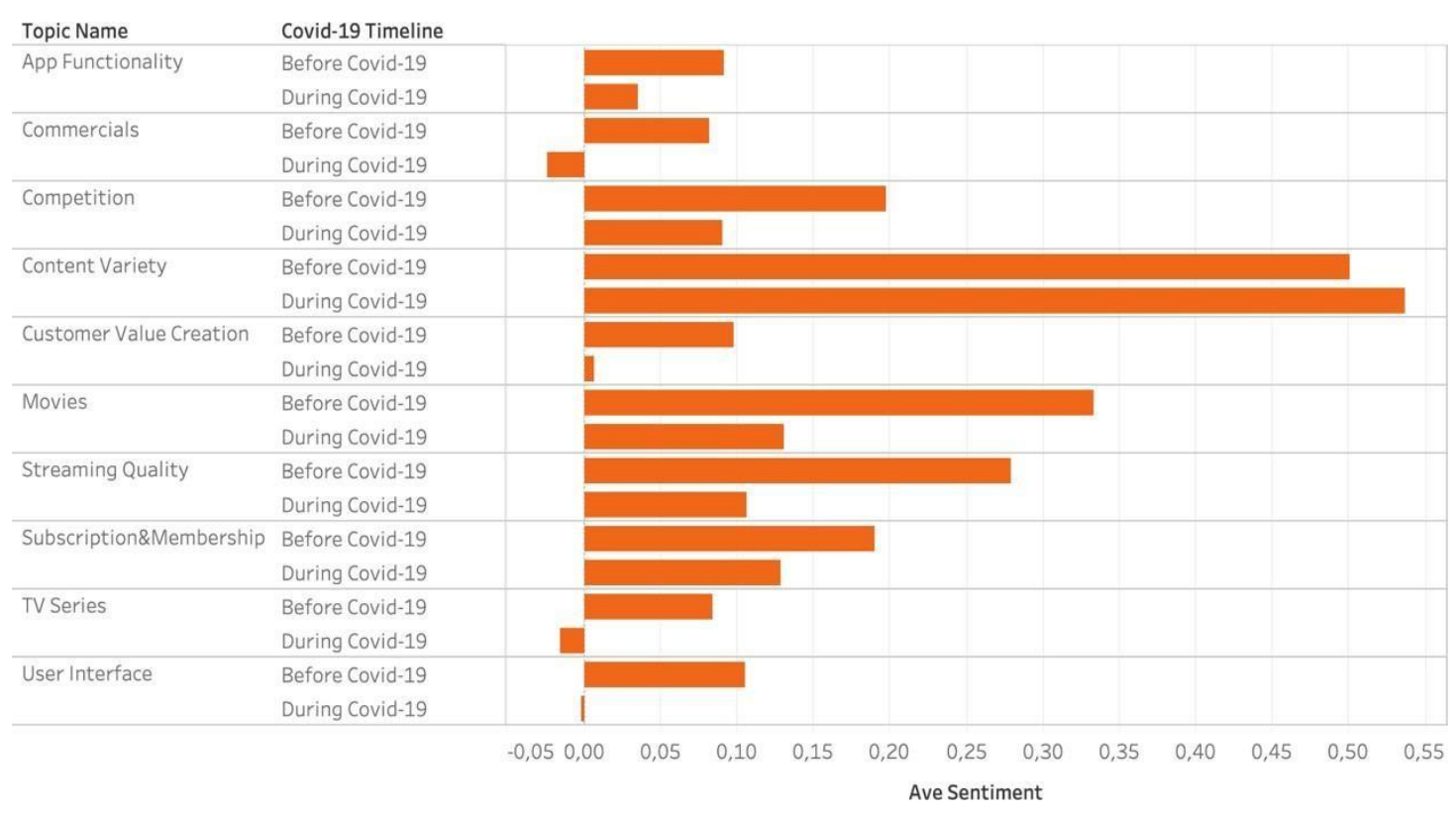

In addition to each topic's general sentiments, breakdowns of sentiments into emotions are essential to understanding the reviews' actual feelings. Figure 7 depicts the detailed sentiments of each topic at pre and post-covid. As also observed in Figure 2, Figure 7 demonstrated that the sense of trust is the most evoked emotion across all topics, regardless of the covid period. Even a noticeable increase is observed in trust during covid.

The rise in emotions applies to almost all the topics during post-pandemic. As one of the most recognized increases, people appreciated the value created by $\mathrm{sVoD}$ services during the pandemic and reflected it in the form of anticipation in their online reviews. 
As can be observed in Figure 7, online reviews are mostly reflecting positive emotions regarding the functionality of the application, TV series, movies, and subscription \& membership.

The most problematic topics seem user interface and streaming quality. To be valid for both, although there are increases in the level of trust after the pandemic, there are even more increases in reflected anger in reviews. According to the opportunity map (Figure 8), the streaming quality is important to the users. However, the satisfaction level is relatively low, hinting that it is an area where the opportunity lies for development.

Figure 7. Detailed Topic-Based Sentiments Before and During Covid-19

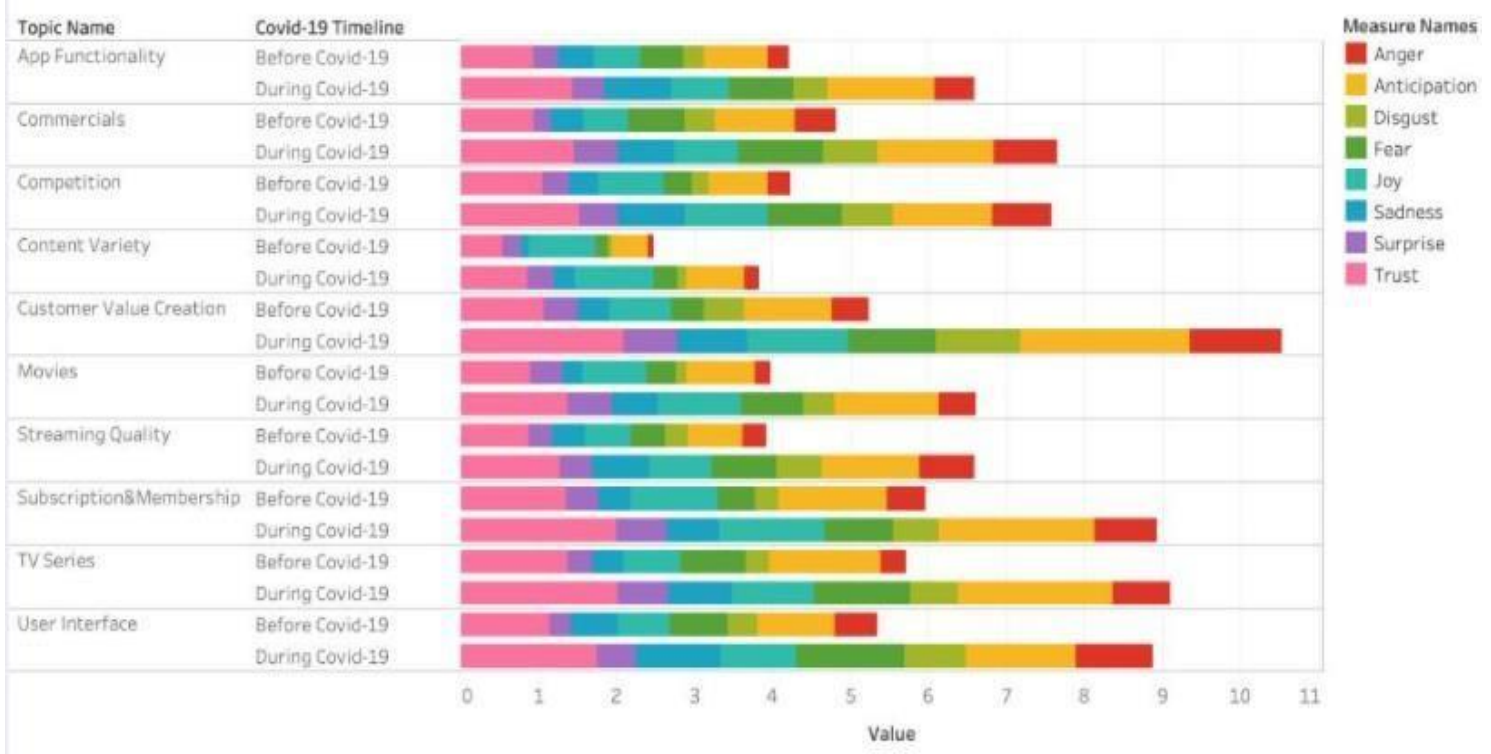

\subsection{Opportunity analysis}

The current study's purpose is to provide an analysis of possible service opportunity improvements for sVoD systems. In this section, using text-data as input and following previous work (Ulwick, 2002; Jeong et al.,2019), an opportunity algorithm is applied to mine these opportunities. To define these opportunities as proposed by Ulwick (2002), we used two dimensions. The first dimension is the level of importance attributed by the customer, and the second is the satisfaction level generated by the service offering (Figure 8). The attributed importance is calculated using topic proportions. As the density of a topic expands, its importance is also expected to increase. The second dimension (satisfaction) is calculated with the use of sentiment scores. The average 
sentiment score receives a value between -1 and 1, where the opposing end of the continuum implies unsatisfaction, and the other end indicates a high level of satisfaction. Before calculating each service dimension (topics), average sentiments per topic were computed by multiplying topic prevalence and document sentiment scores. The opportunity of each service dimension is calculated with a scale of 0-10 (Jeong, et al., 2019), by using the following equation (Ulwick, 2002):

$$
\text { (4) Opportunity }=\text { Importance }+(\text { Importance-Satisfaction })
$$

Table 2 summarizes each service dimension's importance and satisfaction levels with their computed opportunity scores.

Table 2. Results of The Opportunity Analysis

\begin{tabular}{llll}
\hline Topics & Importance & Satisfaction & Opportunity \\
\hline Content Variety & 5,30819 & 10 & 0,61638 \\
Commercials & 6,88152 & 0 & 13,76304 \\
Streaming Quality & 7,94666 & 3,02674 & 12,86658 \\
App Functionality & 5,8553 & 1,66835 & 10,04225 \\
User Interface & 4,18562 & 0,78371 & 7,58753 \\
TV Series & 5,94728 & 0,13394 & 11,76062 \\
Customer Value & 10 & 1,39656 & 18,60344 \\
Movie & 3,58818 & 4,61073 & 2,56563 \\
Subscription and Membership & 0 & 2,14931 & $-2,14931$ \\
Competition & 5,66931 & 4,08875 & 7,24987 \\
\hline
\end{tabular}

The top three service dimensions in terms of importance are streaming quality, commercials, and TV Series. The most satisfying service dimensions are content variety, movies, and competition, where the least satisfied are commercials, user interface, and TV series. Figure 8 exhibits the opportunity landscape for Amazon's sVOD system. The highest opportunities are computed in customer value, commercials, streaming quality, TV Series, and App Functionality. The information in Table 2 provides a preliminary insight into service improvement opportunities. The opportunity scores should be interpreted to include satisfaction and importance levels (see Figure 8 for details).

The opportunity landscape map includes three different groups of service dimensions. 
The first group consists of the dimensions that are served at the right level. These dimensions are either adequately satisfied or attributed as less critical. These dimensions include "movies", "competition", "app functionality"," user interface", and "subscription and membership". Amazon's current service delivery on these topics meet the expectations of its consumers. "Subscription and membership" is the least important topic for consumers, followed by the movie content and user interface. The "user interface" is mostly related to ease of use. The topic mainly covers issues on the variety of language and subtitle options, efficient search function, and ability to locate new additions to the service quickly. Movies have been in the scope of Amazon since its launch in 2006. Starting from this period, Amazon's initial service included renting and purchasing movie content (Wayne, 2018). As a result, Amazon was able to satisfy its users, and the topic became the second most satisfactory service dimension. Between these topics, the highest opportunity lies in "app functionality." Although it creates mediocre importance in consumers' minds, it does not create a decent satisfaction level. It can be concluded that further changes and improvements in these areas will not serve the company.

Figure 8. Opportunity Landscape for sVoD Services

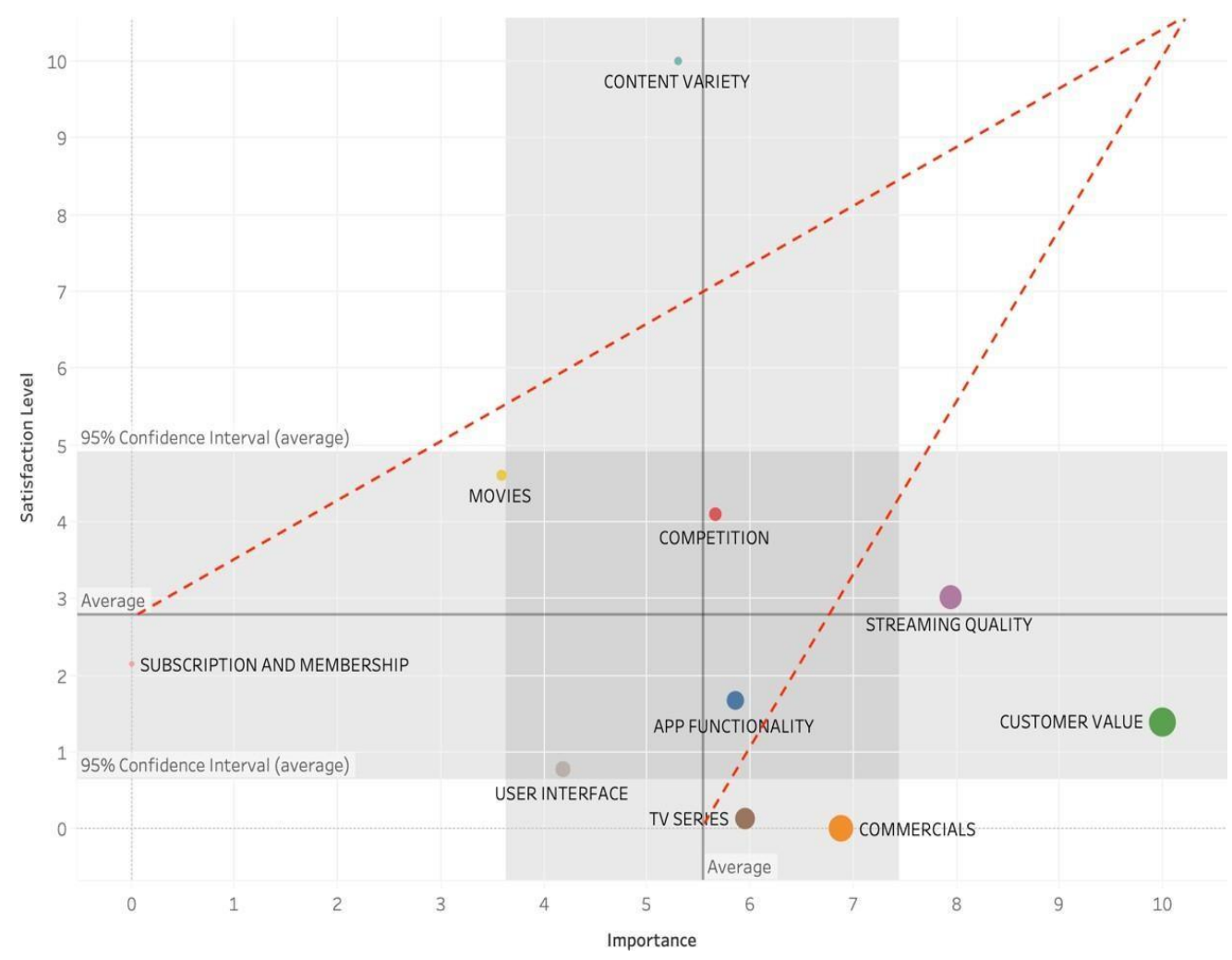


The second group represents over-served topics, positioned at the upper left corner of the opportunity map. The only service dimension in over-served topics is "content variety". Amazon's decision on acquiring certain traditional cable networks over the years, as a result of enriching its content, Amazon also increased the number of subscriptions (Wayne, 2018). Besides the number of subscriptions, the topic also receives the highest satisfaction among consumers. Supplying rich content to the subscribers is one of the most critical aspects of sVoD services' success. Amazon's unprecedented content variety and its policies in augmenting its content have created benefits for the company.

The most important group is the under-served topics as the opportunities lie in this area of the map. These topics' level of importance exceeds their level of satisfaction. According to the opportunity landscape map (Figure 8), these topics include "TV Series", "Commercials", "Streaming Quality", and "Customer Value Creation".

Despite the positive emotions created by the "TV series" (see Figure 4 for details), there are still some opportunities for the company in this service dimension. In addition to content variety, the supplied content's quality is essential in any $\mathrm{s}$ oD system's success. Consumers expect frequent content updates while using sVoD systems, especially for TV Series. Also, as consumers prefer to binge-watch TV content on a subscriptionbased service, their interest decreases faster as their consumption levels increase. Consequently, it becomes harder for the service provider to keep them engaged (Godinho de Matos and Ferreira, 2020). This is especially becoming more problematic during the pandemic. During the pandemic, consumers need more leisure time and entertainment as they spend more time at home and work hours at home increase. Therefore, their content consumption level and their expectations from the content rise, which brings along a lower level of satisfaction (see Figure 6). TV content should provide a high level of variety with frequent content updates. But this is also not a relatively easy task to follow for $\mathrm{sVoD}$ service providers due to intellectual property rights. As a solution, most of them prefer to include original productions (e.g., Amazon originals). Exclusive content should also meet consumer needs, both in terms of variety and quality. We can conclude that consumers seek a high level of variety for the TV series and frequent library updates.

Services are mostly judged by their quality. When sVoD services are taken into 
consideration, the most important two dimensions are content and system quality. System quality is mainly related to the user interface, app functionality, and last but not least, streaming quality. Although the satisfaction level of "streaming quality" receives an average, its importance is so high that the topic is among the under-served service dimension group. Especially during the pandemic, the traffic of $\mathrm{sVoD}$ systems has inflated. As the number of subscribers grows, the service should generate a reasonable streaming quality, including uninterrupted system use and high connection speed (Riekkinen, 2018). The customers also expect high streaming quality through different devices.

The third topic is commercials. This topic serves as one of the top two opportunities for $\mathrm{sVoD}$ service providers. It is the topic that creates the highest dissatisfaction among $\mathrm{sVoD}$ system users. The nature of $\mathrm{sVoD}$ systems requires a commercial-free video streaming service. By the end of 2020, many Amazon customers started to complain about commercials during their streaming.

Most of these ads are provided by IMDb TV The commercials have exceeded during the pandemic, which caused a higher frustration for the users. This situation is also apparent in the opportunity landscape map. sVoD system users expect a commercial-free environment during service use since the business model is based on subscription through payment. A solution in terms of service improvement can be the availability of different membership offers, especially one with a commercial-free option. As Amazon takes the lead, the other sVOD service providers have to observe it to learn from it and not repeat the mistakes (if there are any).

The highest opportunity lies in supplying excellent customer value. Previous studies (Oyedele and Simpson, 2018; Mohd-Any et al.,2015) have defined different value dimensions for streaming services: cognitive effort, convenience value, monetary value, emotional value, and social value. As defined by the terms of the topic (Table 1), this topic addresses users' perception of time and economic value in this context. Time is positively related to cognitive efforts and convenience value. Cognitive effort is mostly connected with ease of use. Convenience value is mainly associated with time and effort. In the context of self-service technology, convenience is users' perception of time and effort associated with service use (Collier and Kimes, 2013). While using sVoD services, customers expect instant and easy access to content, so their expectance for convenience is relatively high. Amazon provides a somewhat fragmented service, 
operating differently on different devices, which creates inconveniences in system use (Wenzel et al., 2016). This is mostly related to Amazon's effort to promote its Fire devices. When compared to the most prominent competitor, Netflix, Amazon's policy can create dissatisfaction. Amazon provides high-quality content with high-definition options but finding shows to stream on Amazon is also a time-consuming task. The tagging of genres and browsing through content is also somewhat harder on Amazon. As users' experience becomes cluttered and complicated, their perceptions of the convenience value again become negative. According to the analysis, the opportunity lies in providing an unfragmented service, the bookmarking option's availability when moving between the devices, personalizing the content with suggestions, and providing standardized operation on every device with a user-friendly interface.

The second value dimension addressed by customers in their reviews was the monetary value they associate with the $\mathrm{sVoD}$ service. SVoD providers offer different subscription fees ranging from free to monthly charges. Amazon has two options for Prime Video. The first option includes a single subscription to their service for $\$ 8.99$ per month. Users can also watch prime videos as an extension of their Prime membership (delivery service) for $\$ 12.99$ monthly, or $\$ 119.00$ annually. The numbers are almost identical with Amazon's closest competitor Netflix. Most of the negative reviews on monetary value is about commercials. As we have discussed in the third under-served topic (commercials), Amazon customers believe that seeing commercials on a paid streaming platform is irritating. One of the reasons $\mathrm{sVoD}$ services are offered to the market is the consumers' negative reactions to advertisements. With the introduction of the sVoD services, consumers are provided with two options: either they accept to watch the advertisements and TV content is free, or they pay for the content and no advertisements in the shows. Taking the negative view of the Amazon users on commercials, stated in the consumer reviews, $\mathrm{sVoD}$ service providers should carefully set the price and the payment options for the consumers so that no advertisement will ever be placed in the shows. By then, sVoD services should exceed customers' expectations and satisfy their value expectations.

\section{CONCLUSION}

The Covid-19 pandemic has increased the interest in video-on-demand platforms. The fact that consumers spend more time at home during the pandemic has accelerated the 
rapid consumption of content and the transition to different platforms without being tied to a single platform.

E-WOM, communication between consumers to share information about a consumed product or service in an online environment, is an essential source for consumers (Wang \& Wang, 2010). Moreover, today, consumers act more encouraged to share their ideas about the product and/or recommend it to others (Cruz et al., 2017). Customer reviews that comprise important information have influenced the consuming behavior of others, and studies indicated that negative comments have more effects on consumers than positive comments (Anaya-Sánchez et al., 2016). Therefore, it is critical to understand customers' emotions through online reviews and take action accordingly as a firm.

This study aims to present the actual customer feelings about sVoD services in general and during pre and post-pandemic and recommend the improvements for sVoD platforms. In the current study, the emotions and sentiments of the sVoD subscribers, based on online customer reviews, were evaluated to understand the stated feelings in the reviews and the actual underlying feelings. The idea was to understand the consumer in-depth, thus recommending strategies to shape the consumer experience to provide excellent service. The results of the study indicated that positive emotions such as trust, anticipation and joy evoked regarding $\mathrm{sVoD}$ were in the majority. When the emotions are examined in more detail, the topics of subscription and membership, user interface and consumer value creation are those with the most positive sentiments. Despite all the positive sentiments, there are still reviewers who prefer and subscribe to competitors and this is the most obvious problem observed in this study for the service provider. Besides, the most noticeable negative emotion is associated with anger and commercials. Comparative study based on pre and post-pandemic emotions indicated that there is increase only in sentiment scores of content variety. In all matters, trust is most apparent emotion observed during pandemic. However, there is non-negligible increase in anger. Furthermore, we define the possible improvement areas that lie in front of the sVoD platform providers based on the value and satisfaction points given by the consumers for each topic through opportunity mapping. Harnessing findings of this study are required to touch the consumer, which is critical for virtual firms. The shift in the customers' emotions and opportunities for the platforms is worth analyzing. In a narrow sense, these platforms are considered the future of $\mathrm{TV}$, the future of entertainment in a broad sense. As Lindlahr (2020) mentioned that the increasing interest in video on 
demand services during the pandemic will continue in the next years. Therefore, understanding customers with their wants and feelings will lead to creating successful business strategies. To have an interactive relationship with customers, it is essential to get to know the customer and approach the customer, and most importantly, to show the customers that their voices are heard.

Like every other study, the study results should be approached carefully, keeping the limitations in mind. One of the practical limitations of the study is that we only analyzed Amazon Prime TV online reviews. According to the statistics, Amazon Prime TV is the market leader in the USA Market. Still, analyzing the available data on other service providers' platforms allows us to have a more collective opinion about $\mathrm{sVoD}$ service performances and the customers' needs. Second, further research could be conducted to understand subscribers' emotions, sentiments, and expectations for particular topics like movies and/or TV series only. A focused approach could provide a more detailed understanding of a specific topic.

\section{REFERENCES}

Abdullah, M. S. F., \& Artanti, Y. (2021). The Effect of Situational Factor, Visual Mer chandising, and Electronic Word of Mouth on Impulsive Buying Behavior on Video on Demand Services Current The Covid-19 Pandemic Crisis. Journal of Business and Behavioural Entrepreneurship, 5(1), 78-91.

Alhidari, A., Iyer, P., \& Paswan, A. (2015). Personal level antecedents of eWOM and purchase intention, on social networking sites. Journal of Customer Behaviour, 14(2), 107-125.

Amazon. (2019). https://press.aboutamazon.com/news-releases/news-release details/amazoncom-announces-fourth-quarter-sales-21-874-billion/

Anaya-Sánchez, R., Molinillo, S., Japutra, A., \& Millán, A. (2016). Exploring the Sense of Belonging, Participation and Trust in Online Communities: A comparison between Spain and United States. International Journal of Marketing, Communication and New Media, 4(6).

Bickart, B., \& Schindler, R. M. (2001). Internet forums as influential sources of consumer information. Journal of interactive marketing, 15(3), 31-40.

Blei, D. M. (2012), Probabilistic Topic Models. Communications of the ACM, 55(4), 77-84.

Blei, D and Lafferty, J.D. (2009). Topic Models. In A.Srivstava and M. Shahami(Eds.), Text Mining Classification, Clustering, and Applications (pp.101-124). Boca Raton: Chapman and Hall/CRC.

Blei, D., Ng, A.Y and Jordan, M.I. (2003). Latent Dirichlet Allocation. Journal of Machine Learning Approach, 3, 993-1022.

Bouma, G.(2009). Normalized (pointwise) Mutual Information in Collacation Extraction. In Proceedings of GSCL, 31-40.

Brindha, D., Jayaseelan, R., \& Kadeswaran, S. (2020). Covid-19 Lockdown, entertainment and paid ott video-streaming platforms: A qualitative study of audience preferences. Mass Communicator: International Journal of Communication Studies, 14(4), 12-16. 
Chang, J. (2015). lda: Collapsed Gibbs Sampling Method for Topic Models. R package version 1.4.2, https://cran.r-project.org/web/packages/lda/lda.pdf.

Collier, J. E., and Kimes, S. E. (2013). Only if it is convenient: Understanding how convenience influences self-service technology evaluation. Journal of Service Research, 16(1), 39-51.

Constantinides, E., \& Fountain, S. J. (2008). Web 2.0: Conceptual foundations and marketing issues. Journal of direct, data and digital marketing practice, 9(3), 231-244. Cruz, M., e Silva, S. C., \& Machado, J. C. (2017). The influence of WOM and Peer Interaction in the Decision-Making Process of Generation $\mathrm{Z}$ within the family.

International Journal of Marketing, Communication and New Media, (2).

Çadırcı Ozansoy, Tuğçe; Sağkaya Güngör, Ayşegül (2015). Electronic Word-of-Mouth Communication in Online Social Networks: The Motivational Antecedents of Electronic Word-of-Mouth (eWOM) Engagement in Online Social Networks in Capturing, Analyzing, and Managing Word-of-Mouth in the Digital Marketplace (pp. 77-102), Hersey, PA, IGI-Global Publications.

Dixit, A., Marthoenis, M., Arafat, S. Y., Sharma, P., \& Kar, S. K. (2020). Binge watching behavior during COVID 19 pandemic: a cross-sectional, cross-national online survey. Psychiatry research, 289, 113089.

Doh, S. J., \& Hwang, J. S. (2009). How consumers evaluate eWOM (electronic wordof-mouth) messages. Cyberpsychology \& behavior, 12(2), 193-197.

Dogruel, L. (2018). Cross-Cultural differences in movie selection. decision-making of German, US, and Singaporean media users for video-on-demand movies. Journal of International Consumer Marketing, 30(2), 115-127.

Elwalda, A., Lü, K., \& Ali, M. (2016). Perceived derived attributes of online customer reviews. Computers in Human Behavior, 56, 306-319.

Erkan, I., \& Elwalda, A. (2018). Your comments are important to me! The impacts of online customer reviews in shopping websites. International Journal of Internet Marketing and Advertising, 12(1), 1-18.

Feinerer, I. and Hornik, K. (2019). tm:Text Mining Package, R package version 0.7-7, https://cran.r-project.org/web/packages/tm/tm.pdf.

Gimpel, G. (2015). The future of video platforms: Key questions shaping the TV and video industry. International journal on media management, 17(1), 25-46.

Godes, D., \& Mayzlin, D. (2004). Using online conversations to study word-of-mouth communication. Marketing science, 23(4), 545-560.

Godes, D., \& Mayzlin, D. (2004). Using online conversations to study word-of-mouth communication. Marketing science, 23(4), 545-560.

Godinho de Matos, M., and Ferreira, P. (2020). The Effect of Binge-Watching on the Subscription of Video on Demand: Results from Randomized Experiments. Information Systems Research, 31(4), 1337-1360.

Güngör, A. S., and Çadırcı, T. O. (2013). Segmenting eWOM engagers on online social networks based on personal characteristics and behaviour. Ekev Academic Review, 17(57), 33-50.

Hannigan, T. R., Haans, R. F., Vakili, K., Tchalian, H., Glaser, V. L., Wang, M., Kaplan, S. and Jennings, P. D. (2019). Topic modeling in management research: Rendering new theory from textual data. Academy of Management Annals, 13 (2), 586632.

Heng, Y., Gao, Z., Jiang, Y., and Chen, X. (2018). Exploring hidden factors behind online food shopping from Amazon reviews: A topic mining approach. Journal of Retailing and Consumer Services, 42, 161-168.

Huang, Y., Liu, H., Li, W., Wang, Z., Hu, X., and Wang, W. (2020). Lifestyles in Amazon: Evidence from online reviews enhanced recommender system. International Journal of Market Research, 62(6), 689-706.

Jeong, B., Yoon, J., and Lee, J. M. (2019). Social media mining for product planning: A product opportunity mining approach based on topic modeling and sentiment 
analysis. International Journal of Information Management, 48, 280-290.

Jockers, M. (2020). syuzhet: Extracts Sentiment and Sentiment Derived Plot Arcs from Text, R package version 1.0-6

https://cran.r-project.org/web/packages/syuzhet/syuzhet.pdf.

Kim, K., Yoon, S., and Choi, Y. K. (2019). The effects of eWOM volume and valence on product sales-an empirical examination of the movie industry. International Journal of Advertising, 38(3), 471-488.

Köster, A., Matt, C., \& Hess, T. (2021). Do All Roads Lead to Rome? Exploring the Relationship Between Social Referrals, Referral Propensity and Stickiness to Video-onDemand Websites. Business \& Information Systems Engineering, 63(4), 349-366.

Kübler, R., Seifert, R., and Kandziora, M. (2020). Content valuation strategies for digital subscription platforms. Journal of Cultural Economics, 1-32.

Leichtman Research Group, Inc. (2020). https://www.leichtmanresearch.com/wp content/uploads/2020/08/LRG-Press-Release-08-28-20.pdf

Li, X., and Hitt, L. M. (2010). Price effects in online product reviews: An analytical model and empirical analysis. MIS quarterly, 809-831.

Lin, T. M., Lu, K. Y., \& Wu, J. J. (2012). The effects of visual information in eWOM communication. Journal of Research in Interactive Marketing. 6(1), 7-26.

Lindlahr, S. (2020). Forecast of Video-on-Demand users by segment worldwide from 2017 to 2025(in million). Statista. https://www.statista.com/forecasts/456771/video- ondemand-users-worldwide-forecast.

Littleton, C. (2014). Linear TV Watching Down, Digital Viewing Up in Nielsen's Q3 Report. Variety, (December 3), [available at http://variety. com/2014/tv/news/linear-tvwatching-down-digital-viewing-up-in-nielsens-q3-report-1201369665/].

Luo, Y. (2020) The Streaming War During the Covid-19 Pandemic.

Mohammad, S., and Turney, P. (2010, June). Emotions evoked by common words and phrases: Using mechanical turk to create an emotion lexicon. In Proceedings of the NAACL HLT 2010 workshop on computational approaches to analysis and generation of emotion in text (pp. 26-34).

Mikos, L. (2020). Film and Television Production and Consumption in Times of the COVID-19 Pandemic-The Case of Germany. Baltic Screen Media Review, 8(1), 30-34. Mohd-Any, A. A., Winklhofer, H., and Ennew, C. (2015). Measuring users' value experience on a travel website (e-value) what value is cocreated by the user?. Journal of Travel Research, 54(4), 496-510.

Naratthawan, T. (2021). Factors Affecting Online Media Streaming Service Subscriptions Behaviors During The Covid-19 Pandemic In Thailand (Doctoral dissertation, Mahidol University).

Nielsen Report on "COVID-19: TRACKING THE IMPACT ON MEDIA CONSUMPTION"https://www.nielsen.com/us/en/insights/article/2020/covid-19-

tracking-the-impact-on-media-consumption/

Newman, D., Lau, J.H., Gieser, K. and Baldwin, T. (2010). Automatic Evaluation of Topic Coherence. In Human Language Technologies: The 2010 Annual Conference of the North American Chapter of the Association for Computational Linguistics , 100-108. Noah, S. (2020). Dual portfolio management strategies of online subscription video on demand (SVOD) companies: a genre perspective. Journal of Media Business Studies, 122.

Oyedele, A., and Simpson, P. M. (2018). Streaming apps: What consumers value. Journal of Retailing and Consumer Services, 41, 296-304.

Riekkinen, J. (2018). Piracy versus netflix: Subscription video on demand dissatisfaction as an antecedent of piracy. In Proceedings of the Annual Hawaii International Conference on System Sciences;. University of Hawai'i at Manoa.

Rinker,T. (2019). "sentimentr:Calculate Text Polarity Sentiment", R package version 2.7-1, https://cran.r-project.org/web/packages/sentimentr/sentimentr.pdf.

Röder, M., Both, A. and Hinneburg, A. (2015). Exploring the Space of Topic Coherence 
Measures. In Proceedings of the eight ACM International Conference on Web Search and Data Mining, 399-408.

Sankar, H., Subramaniyaswamy, V., Vijayakumar, V., Arun Kumar, S., Logesh, R., and Umamakeswari, A. J. S. P. (2020). Intelligent sentiment analysis approach using edge computing-based deep learning technique. Software: Practice and Experience, 50 (5), 645-657.

Sievert, C. and Shirley, K. (2014). LDAvis: A Method for Visualizing and Interpreting Topic Models. In Proceedings of the Workshop on Interactive Language Learning, Visualization, and Inferences, 63-70.

Sijoria, C., Mukherjee, S., \& Datta, B. (2018). Impact of the antecedents of eWOM on CBBE. Marketing Intelligence \& Planning. 36 (5), 528-542.

Statista, Digital Market Outlook (2020) - Segment Report- Digital Media Report 2020 Video-on-Demand.

Susanno, R., Phedra, R., and Murwani, I. A. (2019). The determinant factors of the intention to spend more time binge-watching for Netflix subscriber in Jakarta. Journal of Research in Marketing, 10(3), 807-812.

Statista, number of movies and TV shows subscribers get per dollar on major SVoD platforms in the United States as of September 2020.

https://www.statista.com/statistics/1110891/svod-content-value-for-money-us/

Tashanova, D., Sekerbay, A., Chen, D., Luo, Y., Zhao, S., and Zhang, T. (2020). Investment Opportunities and Strategies in an Era of Coronavirus Pandemic. SSRN 3567445.

Thakur, R. (2018). Customer engagement and online reviews. Journal of Retailing and Consumer Services, 41, 48-59.

Trenz, M. and Berger, B. (2013). "Analyzing Online Customer Reviews - An Interdisciplinary Literature Review and Research Agenda". ECIS 2013 Completed Research. 83. https://aisel.aisnet.org/ecis2013_cr/83.

Ulwick, A. W. (2002). Turn customer input into innovation. Harvard business review, 80(1), 91-98.

Vega, M. T., Perra, C., De Turck, F., and Liotta, A. (2018). A review of predictive quality of experience management in video streaming services. IEEE Transactions on Broadcasting, 64(2), 432-445.

Wang, C. C., \& Wang, Y. T. (2010). Persuasion effect of e-WOM: The impact of involvement and ambiguity tolerance. Journal of Global Academy of Marketing, 20(4), 281-293.

Wang, Y., Wang, Z., Zhang, D., and Zhang, R. (2019). Discovering cultural differences in online consumer product reviews. Journal of Electronic Commerce Research, 20(3), 169-183.

Wayne, M. L. (2018). Netflix, Amazon, and branded television content in subscription video on-demand portals. Media, Culture \& Society, 40(5), 725-741.

Wenzel, P., Mahle, I., and Pätzmann, J. U. (2016). Streaming Services and Service Design: An Analysis of Netflix and Amazon Video Based on the Gap Model by Parasuraman, Berry and Zeithaml. Markenbrand, (5/2016), 20-31.

Westbrook, R.A. (1987), "Product/consumption-based affective responses and post purchase processes", Journal of Marketing Research, Vol. 24 No. 3, pp. 258-70.

Wu, T. (2013). Netflix's war on Mass Culture. New Republic, 4.

Yayl, A., and Bayram, M. (2012). E-WOM: The effects of online consumer reviews on purchasing decisions. International Journal of Internet Marketing and Advertising, 7(1), 51-64. 


\section{How to cite this article:}

Çadırcı, T. O.; Güngör, A. S.; \& Kılıç, S. (2022). The Voice of the Consumer on sVoD Systems During Covid-19: A Service Opportunity Mining Approach, International Journal of Marketing, Communication and New Media. Special Issue on Marketing in the Context of COVID-19, January 2022, 5-29. 